\title{
Fully Informed Classification Systems Simpler, Maybe Better
}

\author{
Ana Fernandes ${ }^{1}$ (D), Filomena Carvalho ${ }^{2,3}$ (D), Jorge Ribeiro ${ }^{4}$ (D), \\ Dinis Vicente $^{5}(D)$, João Faria ${ }^{5}(D)$, Margarida Figueiredo ${ }^{6}(D$, \\ António Capita ${ }^{7}$ (D) José Neves $^{8(\mathbb{\triangle})}$ (D), and Henrique Vicente ${ }^{8,9}$ (D) \\ ${ }^{1}$ Departamento de Química, Escola de Ciências e Tecnologia, \\ Universidade de Évora, Évora, Portugal \\ anavilafernandes@gmail.com \\ 2 Departamento de Ciências Jurídicas, Escola Superior de Tecnologia e Gestão \\ de Leiria, Instituto Politécnico de Leiria, Leiria, Portugal \\ filomena. carvalho@ipleiria.pt \\ 3 Centro de Investigação IJP - Instituto Jurídico Portucalense, Leiria, Portugal \\ ${ }^{4}$ Escola Superior de Tecnologia e Gestão, ARC4DigiT - Applied Research \\ Center for Digital Transformation, Instituto Politécnico de Viana do Castelo, \\ Viana do Castelo, Portugal \\ jribeiro@estg.ipvc.pt \\ 5 Escola Superior de Tecnologia e Gestão de Leiria, \\ Instituto Politécnico de Leiria, Leiria, Portugal \\ dinisvicente98@gmail.com, joaocfarialo@gmail.com \\ ${ }^{6}$ Departamento de Química, Escola de Ciências e Tecnologia, \\ Centro de Investigação em Educação e Psicologia, \\ Universidade de Évora, Évora, Portugal \\ mtf@uevora.pt \\ 7 Instituto Superior Técnico Militar, Luanda, Angola \\ antoniojorgecapita@gmail.com \\ ${ }^{8}$ Centro Algoritmi, Universidade do Minho, Braga, Portugal \\ jneves@i.uminho.pt, hvicente@uevora.pt \\ 9 Departamento de Química, Escola de Ciências e Tecnologia, \\ Centro de Química de Évora, Universidade de Évora, Évora, Portugal
}

\begin{abstract}
This paper presents the starting point to adverse event reporting and learning systems designed to describe and prevent unfavorable happenings in Public Services organizations. To achieve this goal, the Eindhoven's Classification Method was changed to house such incidents. On the other hand, the evolutionary process of the knowledge body of such systems is to be understood as a process of energy devaluation, i.e., their data/information/knowledge will be represented and handled as pure energy transactions, being such procedures and the respective outcomes object of formal proof under a Proof Theoretical approach to Problem Solving.
\end{abstract}

Keywords: Public services $\cdot$ Eindhoven classification method $\cdot$ Knowledge representation and reasoning $\cdot$ Logic programming $\cdot$ Entropy 